\title{
ECTOPIC PREGNANCIES AFTER ASSISTED REPRODUCTIVE TECHNOLOGIES
}

\author{
Marieta Iskilieva $^{1}$, Nadya Magunska $^{1}$, Emil Kovachev ${ }^{2}$, Atanas Shterev $^{1}$ \\ ${ }^{1}$ SAGBAL Dr. Shterev Hospital, Sofia \\ ${ }^{2}$ Department of Obstetrics and Gynecology, Faculty of Medicine, \\ Medical University of Varna
}

\begin{abstract}
INTRODUCTION: One of the complications of assisted reproductive technologies (ART) is development of pregnancy beyond the endometrium of the uterine cavity - ectopic pregnancy (EP). There are different factors that influence the frequency of EPs after ART. On the one hand, the characteristics of ovarian hyperstimulation, and on the other - women's age, hormonal status, history of previous pregnancy, etc.

AIM: This is a retrospective study, whose purpose is to examine and evaluate different risk factors in women with EP after ART.

MATERIALS AND METHODS: This is a retrospective study conducted between 01.2013 and 12.2017 at the Dr. Shterev Medical Complex, Sofia. We have analyzed 5229 cycles - 3773 IVF/ICSI cycles, 875 FrET cycles, and 581 cycles with egg donation. A total of 1712 clinical, intrauterine, ectopic and heterotopic pregnancies after ART were included in our study.

RESULTS AND DISCUSSION: The rate of EPs after ART in our group was 2.4\%, which corresponds to previous data, published in the scientific literature. We have also identified some rare forms of EP cornual and cervical pregnancy. The analysis we conducted showed that probable risk factors for EP are tubal infertility and associated chronic inflammatory processes of the fallopian tubes, increased number of transferred embryos, use of additional techniques - assisted hatching, polycystic ovary syndrome (PCOS), and previous surgery in the pelvis.

CONCLUSION: EP is a global medical emergency and its incidence increases following treatment of infertility. Early diagnosis and prompt intervention are crucial in order to diminish the morbidity and mortality, and to avoid complications thereafter.
\end{abstract}

Keywords: ectopic pregnancy, ART, risk factors

Address for correspondence:

Marieta Iskilieva

SAGBAL Dr. Shterev

26-31 Hristo Blagoev St

1330 Sofia

e-mail:marieta.t.i@abv.bg

Received: September 5, 2019

Accepted: December 21, 2019

\section{INTRODUCTION}

Since the birth of the first successful in vitro fertilisation (IVF) baby in 1978, there has been an increased demand for assisted reproductive technologies (ART), including intrauterine insemination and IVF-embryo transfer (IVF-ET).

One of the most serious complications after ART is development of pregnancy beyond the en- 
dometrium of the uterine cavity - ectopic pregnancy (EP).

EP is estimated to constitute $1-2 \%$ of all natural conceptions and the incidence increases following ART. The prevalence of EP following ART ranges between 2.1 to $8.6 \%$ of all pregnancies and it can reach up to $11 \%$ in female patients with a history of tubal factor infertility $(1,2,3,4)$.

EP is the leading cause of medical emergen$c y$, and the leading cause of maternal morbidity and mortality. Early diagnosis and proper intervention have a critical effect on the morbidity and mortality of this condition. Several factors have been associated with an increased risk of EP after ART chronic inflammatory diseases of the pelvis, endometriosis, previous ectopic pregnancy, vaginal infections, increased uterine contractility and retrograde movement of transferred embryo, number of embryos transferred, endometrial thickness on the day of transfer, additional techniques - assisted hatching, etc. (5).

\section{AIM}

The purpose of this study is to analyze the risk factors for the development of EP related to the characteristics of the patients included in the group, as well as the factors related to the ART procedure itself.

\section{MATERIALS AND METHODS}

This is a retrospective study conducted between 01.2013 and 12.2017 at the Dr. Shterev Medical Complex, Sofia. We have analyzed 5229 cycles - 3773 IVF/ ICSI cycles, 875 FrET cycles, and 581 cycles with egg donation. A total of 1712 clinical intrauterine ectopic and heterotopic pregnancies after ART were included in our study. Of those 41 (2.4\%) were ectopic

We summarized the results from a total of 41 women with EPs after ART. As a control group, we have used the data from 42 women with EP after natural conception. The collected data included patient demographic characteristics, medical and obstetric history, infertility diagnosis, method of treatment of ectopic pregnancy, and specific parameters of ART.

EPs were reported when the gestational sac was confirmed to be outside the uterus by ultrasonography or by high serial serum $\beta$-human chorionic gonadotropin values in the absence of an intrauterine pregnancy on ultrasonography. All cases with
EP were diagnosed during the first trimester of the pregnancy $(6,7)$. The treatment of established EP was operative - by laparoscopy. EP rates were classified, based on the type of in vitro fertilization-embryo transfer (IVF-ET) procedure, as either fresh or frozen cycles. A fresh cycle was reported when the oocytes were retrieved and the resultant embryos transferred during the current IVF-ET cycle. A frozenthawed cycle was reported when cryopreserved embryos, resulting from a previous cycle, were thawed and transferred during the current IVF-ET cycle.

Risk factors evaluated were patient age, parity, infertility diagnosis (male factor, tubal factor, endometriosis, hormonal factor), use of assisted hatching $(\mathrm{AH})$, day of embryo transfer, number of embryos transferred, polycystic ovary syndrome (PCOS), endometriosis, and endometrial thickness on the day of ET.

We compared the distribution of these risk factors between EPs after ART and pregnancies after spontaneous conception using the $X^{2}$ test at a significance level of $P<.05$.

\section{RESULTS}

A total of 83 women were included - 41 of them with EP after ART (10 after frozen ET and 31 after fresh ET) and 42 women with EP after spontaneous conception.

The total rate of EP was $2.4 \%$ of women after ART (41 out of 1712 clinical pregnancies). The rate of EP after fresh embryo transfer (ET) was 2.3\% (31 out of 1371 clinical pregnancies),while after frozen embryo transfer (FrET) it was $2.9 \%$ (10 out of 341 clinical pregnancies).

The average age of all women with EP was under 35 years: 31.4 years for those after ART and 31.0 years for those in the control group.

Higher BMI values (24.07) were identified in women after ART, compared with spontaneous pregnancies with BMI of 21.64, with a statistically significant difference - $\mathrm{p}<0.020$.

In 39\% of women after ART, we detected PCOS, whereas in the control group - the incidence was $9.5 \%$. We found statistically significant difference $\mathrm{p}<0.002$ between these two groups. 
The collected data showed histologically detected endometriosis in $7.3 \%$ of women after ART with $\mathrm{EP}$, and $4.8 \%$ in spontaneous pregnancies with EP.

Our analysis also showed that $7.3 \%$ of the patients after ART and EP had a previous EP, while in the control group it was $14.3 \%$. In $31.7 \%$ of the patients after ART and EP we collected data for previous surgery in the pelvis. The percentage is similar to spontaneously pregnant women - 31\%. Data for inflammatory processes in the pelvis was found in $68.3 \%$ of women, pregnant after ART, and in $64.3 \%$ in the control group.

Data from ART procedures shows that according to the type of infertility, the couples with male sterility factor were $39 \%$. In a consecutive research, we found tubal factor of infertility in $26.8 \%$ of women, unexplained infertility in $19.5 \%$, hormonal infertility in $9.8 \%$, and endometriosis as an infertility factor in $4.9 \%$.

ET was performed on day 3 or 5 in $43.9 \%$ and $43.9 \%$ of the cases, respectively. Transfers of $1 \mathrm{em}-$ bryo were made in only $12.2 \%$ of the women.

Intracytoplasmic sperm injection (ICSI)/intracytoplasmic morphologically selected sperm injection (IMSI) procedures were applied in $71.3 \%$ of the cases. Assisted hatching technique was used in almost half of the cases with EP - 46.3\%.

The endometrial thickness on the day of ET was $11.32 \mathrm{~mm}$. In regard to the localization of ectopic pregnancy, in our study we found tubal EP in $95.1 \%$. Cervical pregnancy developed in $1.2 \%$, and pregnancy in the uterine horn was also diagnosed in $1.2 \%$.

\section{DISCUSSION}

The overall ectopic pregnancy rate after ART in our study was $2.4 \%$, similar to previous publications. Several research groups have shown that the risk of EP increases with advanced age, particularly in women over 35 years $(8,9,10,11)$. An explanation for this correlation with age could be the existence of a higher probability of exposure to most other risk factors with advancing age, increase in chromosomal abnormalities in trophoblastic tissue and age-related changes in the tubal function. However, there are also groups that have failed to detect an association between maternal age and the risk of developing EP as in our results $(12,13,14)$. The average age of women in both groups of the study was under 35 years.
High BMI is a risk factor for a number of complications during pregnancy. In both groups, BMI was within the established norms, despite the statistical difference between the two groups.

Endometriosis and its treatment have also been associated with the development of EP. Endometriosis leads to the formation of pelvic and tubal adhesions, which could result in abnormal tubal function and impaired transport of blastocysts into the uterine cavity (15). A history of EP is considered as a major risk factor for subsequent recurrence of EP (16). Probable reasons for it could be previous surgical interventions, chronic inflammation of the fallopian tubes or pelvic inflammatory disease. In contrast, our study has not supported this fact and we found previous EP only in a small number of cases $(7.3 \%)$.

PCOS is associated with the hyperphysiological level of estradiol in women after controlled ovarian hyperstimulation and therefore a possible cause of EP (17). In addition to this fact, in a group with women after ART and ectopic pregnancies, we diagnosed PCOS in $39 \%$ of them. The results obtained for the incidence of PCOS and EP also correlate with the average age of women - under 35 years in both groups.

Over the last 40 years, the incidence of EP has increased with the rise of sexually transmitted infections and the associated inflammatory changes in the fallopian tubes. Chlamydia trachomatis infection is the most common sexually transmitted infection worldwide. The immune response to this infection may lead to tubal occlusion, EP and infertility $(18,19)$. The association between chlamydial infection and EP is most commonly found in young women under 35. Most of the women in both groups are under 35 years, so we expected a higher incidence of chronic inflammation of the fallopian tubes, as our results showed $(68.3 \%$ after ART and $64.3 \%$ in the control group).

Multiple studies have demonstrated that women with tubal factor infertility have an increased risk of EP after ART, compared with those with other types of infertility diagnoses. In our study we established a tubal factor of infertility more often - in $26.8 \%$ of cases (Table 1 ).

Several studies have investigated the development of EP during IVF-ET and many technical is- 
Table 1. Risk factors and types of EP

\begin{tabular}{|c|c|c|}
\hline $\begin{array}{l}\text { Risk Factors and Types } \\
\text { of EP }\end{array}$ & $\begin{array}{l}\text { Control } \\
\text { Group }\end{array}$ & $\begin{array}{l}\text { Research } \\
\text { Group }\end{array}$ \\
\hline \multicolumn{3}{|l|}{ Age } \\
\hline Mean & 31.4 & 31.4 \\
\hline SD & 4.45 & 5.38 \\
\hline $\mathrm{T}$ & 0.03 & \\
\hline Df & 81 & \\
\hline $\mathrm{P}$ & 0.975 & \\
\hline Under 35 years & $78.6 \%$ & $80.5 \%$ \\
\hline Above 35 years & $21.4 \%$ & $19.5 \%$ \\
\hline $\mathrm{X} 2$ & 0.047 & \\
\hline Df & 1 & \\
\hline $\mathrm{P}$ & 0.829 & \\
\hline \multicolumn{3}{|l|}{ BMI } \\
\hline Mean & 21.6 & 24.1 \\
\hline SD & 2.15 & 6.28 \\
\hline $\mathrm{T}$ & 2.37 & \\
\hline Df & 81 & \\
\hline $\mathrm{P}$ & 0.02 & \\
\hline Endometriosis & $4.8 \%$ & $7.3 \%$ \\
\hline $\mathrm{P}$ & 0.676 & \\
\hline Previous tubal pregnancy & $14.3 \%$ & $7.3 \%$ \\
\hline $\mathrm{P}$ & 0.483 & \\
\hline PCOS & $9.5 \%$ & $39 \%$ \\
\hline $\mathrm{X} 2$ & 9.870 & \\
\hline Df & 1 & \\
\hline $\mathrm{P}$ & 0.002 & \\
\hline $\begin{array}{l}\text { Previous abdominal op- } \\
\text { erative interventions }\end{array}$ & $31 \%$ & $31.7 \%$ \\
\hline $\mathrm{X} 2$ & 0.005 & \\
\hline Df & 1 & \\
\hline $\mathrm{P}$ & 0.941 & \\
\hline Salpingitis & $64.3 \%$ & $68.3 \%$ \\
\hline $\mathrm{X} 2$ & 0.149 & \\
\hline Df & 1 & \\
\hline $\mathrm{P}$ & 0.699 & \\
\hline
\end{tabular}

Type of sterility

Male factor $\quad 39 \%$

Endometriosis $\quad 4.9 \%$

Hormonal $\quad 9.8 \%$

Unexplained $\quad 19.5 \%$

Tubal 26.8\%

Type of ART procedure

ISCI/IMSI $\quad 71.3 \%$

IVF $\quad 12 \%$

IVF/ICSI $\quad 16.7 \%$

Fresh/Frozen ET sues of the treatment have been proposed as risk factors for EP. These risk factors include an altered hormonal milieu due to ovarian stimulation, the day and stage of embryo transfer, multiple embryo transfer, volume of transfer media and position of the catheter. The exact mechanism responsible for EP after ART is unknown. Possible mechanisms involve diminished endometrial receptivity. Higher circulating concentrations of oestradiol during stimulated cycles could also be associated with a reverse migratory process of the transferred embryos. One of the likely mechanisms is the migration of the transferred embryos up into the fallopian tubes due to the mechanical movement of fluids inside the uterus. An enlarged fallopian tube, due to an inflammatory process, can facilitate the passage of embryos into the tubes and cause EP $(20,21)$.

The 'quality' of the embryo may also contribute to the risk of EP after IVF. A poor quality embryo may be likely to undergo ectopic implantation and also increase in risk of EP.

Studies have shown reduced uterine contractility in the luteal phase, therefore it is suggested that the incidence of ectopic pregnancy should be lower at ET on day 5. It is also suggested that a larger size of the blastocyst may reduce the chances of the embryo migrating to the fallopian tube. In contrast to this fact, in our study we found ET on day 3 in $43.9 \%$ of pregnancies and similarly on day 5 in $43.9 \%$ of cases. Each embryo has an independent implantation potential, and therefore the risk of EP increases with the number of transferred embryos $(22,24)$. Similarly to previous reports, we found a probable relationship between the risk of EPs and the number of embryos transferred during an ART cycle. Only in 12, 2\% of women after ART and EP, there was data for transfer of 1 embryo.

Assisted hatching (AH) has been proposed as a risk factor for developing EP after IVF $(25,26)$. AH facilitates the process of implantation of embryos by providing easier and earlier contact between the embryo and the endometrium and facilitating the transport of growth factors necessary for embryonic development. Embryos with additional techniques were probably implanted earlier. In this way, it is possible to increase the incidence of EP, because of this earlier implantation the embryos migrate into the fallopian 
Marieta Iskilieva, Nadya Magunska, Emil Kovachev et al.

\begin{tabular}{|c|c|c|}
\hline Fresh ET & & $75.6 \%$ \\
\hline Frozen ET & & $24.4 \%$ \\
\hline \multirow[t]{2}{*}{$95 \% \mathrm{CI}$} & & $59.7 / 87.6$ \\
\hline & & $12.4 / 40.3$ \\
\hline $\mathrm{P}$ & & 0.001 \\
\hline \multicolumn{3}{|c|}{ Type ectopic pregnancy } \\
\hline Tubal & $97.6 \%$ & $95.1 \%$ \\
\hline Cornual & $0 \%$ & $2.4 \%$ \\
\hline Cervical & $2.4 \%$ & $2.4 \%$ \\
\hline
\end{tabular}

tubes and do not return to the uterine cavity. Our results were similar - we used AH in $46.3 \%$ of ART in women with EP.

The rate of EP after fresh and frozen ET was $2.3 \%$ and $2.9 \%$, respectively, and without significant difference, in contrast to previous publications. But in the group with EP after ART we found more cases after fresh ET, which confirms the negative effect of ovarian hyperstimulation on endometrial receptivity, as well as possibly increased uterine contractility in stimulated cycles $(28,27,28,29,30)$.

The rare forms of EPs after ART were: cervical $(2.4 \%)$ and cornual $(2.4 \%)$. Our results were consistent with those published (31).

\section{CONCLUSION}

EP is a global medical emergency and its incidence increases following treatment of infertility. Early diagnosis and prompt intervention are crucial in order to diminish the morbidity and mortality and to avoid complications thereafter.

It is important to recognize the risk factors for EP in women undergoing ART, because the incidence is higher than it is in the general population. Strategies needed to reduce this risk are: choosing a day for ET, number of embryos for transfer, ET technique, good hormonal preparation of the endometrium, prophylaxis of inflammatory diseases of the female genital organs, etc.

Further investigations are needed to evaluate all risk factors for EP after ART.

\section{REFERENCES}

1. Shaw JL, Dey SK, Critchley HO, Horne AW. Current knowledge of the aetiology of human tub- al ectopic pregnancy. Hum Reprod Update. 2010;16(4):432-44. doi: 10.1093/humupd/dmp057.

2. Vichnin M. Ectopic pregnancy in adolescents. Curr Opin Obstet Gynecol. 2008;20(5):475-8.

3. Farquhar CM. Ectopic pregnancy. Lancet. 2005;366(9485):583-91. doi: 10.1016/ S0140-6736(05)67103-6.

4. Varma R, Gupta J. Tubal ectopic pregnancy. BMJ Clin Evid. 2009;2009. pii: 1406.

5. Chang HJ, Suh CS. Ectopic pregnancy after assisted reproductive technology: what are the risk factors? Curr Opin Obstet Gynecol. 2010;22(3):202-7. doi: 10.1097/GCO.0b013e32833848fd.

6. Xiao GH, Chen DJ, Sun XF, She RQ, Mai YM. Abdominal pregnancy: full-term viable baby. Eur J Obstet Gynecol Reprod Biol. 2005;118(1):117-8. doi: 10.1016/j.ejogrb.2004.04.027.

7. Ramachandran K, Kirk P. Massive hemorrhage in a previously undiagnosed abdominal pregnancy presenting for elective cesarean delivery. Can J Anaesth. 2004;51(1):57-61. doi: 10.1007/BF03018548.

8. Patil M. Ectopic pregnancy after infertility treatment. J Hum Reprod Sci. 2012;5(2):154-65. doi: 10.4103/0974-1208.101011.

9. Parashi S, Moukhah S, Ashrafi M. Main risk factors for ectopic pregnancy: a case-control study in a sample of Iranian women. Int J Fertil Steril. 2014;8(2):147-54.

10. Rana P, Kazmi I, Singh R, Afzal M, Al-Abbasi FA, Aseeri A, et al. Ectopic pregnancy: a review. Arch Gynecol Obstet. 2013;288(4):747-57. doi: 10.1007/ s00404-013-2929-2.

11. Santos-Ribeiro S, Tournaye H, Polyzos NP. Trends in ectopic pregnancy rates following assisted reproductive technologies in the UK: a 12-year nationwide analysis including 160000 pregnancies. Human Reprod (Oxford, England). 2016;31(2):393402. doi: 10.1093/humrep/dev315.

12. Malak M, Tawfeeq T, Holzer H, Tulandi T. Risk factors for ectopic pregnancy after in vitro fertilization treatment. J Obstet Gynaecol Can. 2011;33(6):617-9. doi: 10.1016/S1701-2163(16)34910-6.

13. Weigert M, Gruber D, Pernicka E, Bauer P, Feichtinger W. Previous tubal ectopic pregnancy raises the incidence of repeated ectopic pregnancies in in vitro fertilization-embryo transfer patients. J Assist Reprod Genet. 2009;26(1):13-7. doi: 10.1007/ s10815-008-9278-2. 
14. Li C, Meng CX, Zhao WH, Lu HQ, Shi W, Zhang J. Risk factors for ectopic pregnancy in women with planned pregnancy: a case-control study. Eur J Obstet Gynecol Reprod Biol. 2014;181:176-82. doi: 10.1016/j.ejogrb.2014.07.049.

15. Hunter RH. Tubal ectopic pregnancy: a pathophysiological explanation involving endometriosis. Hum Reprod. 2002; 17(7):1688-91. doi: 10.1093/ humrep/17.7.1688.

16. Malak M, Tawfeeq T, Holzer H, Tulandi T. Risk factors for ectopic pregnancy after in vitro fertilization treatment. J Obstet Gynaecol Can. 2011;33(6):617-9. doi: 10.1016/ S1701-2163(16)34910-6.

17. Wang J, Wei Y, Diao F, Cui Y, Mao Y, Wang W, et al. The association between polycystic ovary syndrome and ectopic pregnancy after in vitro fertilization and embryo transfer, Am J Obstet Gynecol. 2013;209(2):139.e1-9. doi: 10.1016/ S1701-2163(16)34910-6.

18. Ankum WM, Mol BW, Van der Veen F, Bossuyt PM. Risk factors for ectopic pregnancy: A metaanalysis. Fertil Steril. 1996;65(6):1093-9

19. Bakken IJ. Chlamydia trachomatis and ectopic pregnancy: recent epidemiological findings. Curr Opin Infect Dis. 2008;21(1):77-82. doi: 10.1097/ QCO.0b013e3282f3d972.

20. Strandell A, Thorburn J, Hamberger L. Risk factors for ectopic pregnancy in assisted reproduction. Fertil Steril. 1999;71(2):282-6. doi: 10.1016/ S0015-0282(98)00441-5.

21. Li C, Zhao WH, Zhu Q, Cao SJ, Ping H, Xi X, et al. Risk factors for ectopic pregnancy: a multi-center case-control study. BMC Pregnancy Childbirth. 2015;15:187. doi: 10.1186/s12884-015-0613-1.

22. Bu Z, Xiong Y, Wang K, Sun Y. Risk factors for ectopic pregnancy in assisted reproductive technology: a 6-year, single-center study. Fertil Steril. 2016;106(1):90-4. doi: 10.1016/j. fertnstert.2016.02.035.

23. Yanaihara A, Yorimitsu T, Motoyama H, Ohara M, Kawamura T. Clinical outcome of frozen blastocyst transfer; single vs. double transfer. J Assist Reprod Genet. 2008;25(11-12):531-4. doi: 10.1007/ s10815-008-9275-5.
24. Cheng LY, Lin PY, Huang FJ, Kung FT, Chiang HJ, Lin YJ, et al. Ectopic pregnancy following in vitro fertilization with embryo transfer: a single-center experience during 15 years. Taiwan J Obstet Gynecol. 2015; 54: 541-5. doi: 10.1016/j.tjog.2015.08.004.

25. Jun SH, Milki AA. Assisted hatching is associated with a higher ectopic pregnancy rate. Fertil Steril. 2004;81(6):1701-3. doi: 10.1016/j. fertnstert.2003.10.042.

26. Edi-Osagie E, Hooper L, Seif MW. The impact of assisted hatching on live birth rates and outcomes of assisted conception: a systematic review. Hum Reprod. 2003;18(9):1828-35. doi: 10.1093/humrep/ deg334.

27. Polyzos NP, Devroey P. Significantly lower ectopic pregnancy rates after frozen embryo transfer: implications toward segmentation of in vitro fertilization treatment. Fertil Steril. 2012; 98(6):1419-20. doi: 10.1016/j.fertnstert.2012.08.044.

28. Huang B, Hu D, Qian K, Ai J, Li Y, Jin L, et al. Is frozen embryo transfer cycle associated with a significantly lower incidence of ectopic pregnancy? An analysis of more than 30,000 cycles. Fertil Steril. 2014; 102(5):1345-9. doi: 10.1016/j. fertnstert.2014.07.1245.

29. Check JH, Choe JK, Katsoff B, Krotec JW, Nazari A. Ectopic pregnancy is not more likely following fresh vs frozen embryo transfer. Clin Exp Obstet Gynecol,. 2005;32(2):95-6.

30. Decleer W, Osmanagaoglu K, Meganck G, Devroey P. Slightly lower incidence of ectopic pregnancies in frozen embryo transfer cycles versus fresh in vitro fertilization-embryo transfer cycles: a retrospective cohort study. Fertil Steril. 2014; 101(1):162-5. doi: 10.1016/j.fertnstert.2013.10.002.

31. Johnson N, McComb P, Gudex G. Heterotopic pregnancy complicating in vitro fertilization. Aust N Z J Obstet Gynaecol. 1998; 38(2):151-5. doi: 10.1111/j.1479-828x.1998.tb02989.x. 